\title{
Cities in Flight: A Descriptive Examination of the Tropical City Imagined in Twentieth Century Science Fiction Cover Art
}

\author{
Christopher B. Menadue
}

James Cook University, Australia

\begin{abstract}
A search for imaginary cities and city-like objects portrayed in twentieth century science fiction magazine cover art employed digital tools and followed a PRISMA methodology for systematic analysis. The findings include a correlation between indigenous peoples being portrayed as possessing less advanced technology than human visitors or human city builders in the tropics. Human cultural tropes are identified in the depiction of indigenous peoples, and trends over time in the increasing sophistication of portrayals, and a decline in gratuitously sexual artwork are visible, which supports findings of other work on changing cultural perceptions of the tropics found in science fiction. Notable themes were the tropics as a place of conflict, simplistic depictions of women, the difference between the portrayal of jungle and desert environments and the colonial mythology perpetuated in cover art over this period. Science fiction cities of the tropics were often still or devoid of life, rather than vibrant, active places. An intriguing finding was that building a filtering model for tropical environments in a science fiction setting leads naturally to a consideration of how the concept of the tropics is based on arbitrary, Earthly, cartographic conventions, which do not exist on other worlds. This difference highlights the value-laden meaning of tropical environments and societies applied by the 'alien,' whether European colonist or visiting Earthling, and that the inhabitants of the tropics are not bound by these conventions.
\end{abstract}

iving cities in the tropics can be conceived through the imagination as created spaces concerned with peopled and lived experiences interacting with material, cultural and natural environments (Lundberg, 2018, p.1). The process of tropical 
space and place-making in representations of the tropics in science fiction art is especially interesting as it offers de facto an outsider, alien, perspective. Myths, narratives, cultural and natural landscapes, the tropical city, and visions of the tropics, appear in science fiction art. One particularly arresting image inspired this investigation (Fig.1). Akin to one of Henri Cartier-Bresson's photographic Decisive Moments (Cartier-Bresson, 2015) it provides dense, rich thematic content which merges a multitude of concepts in one fleeting instant. A flying city is placed in a tropical jungle setting being watched by a person depicted, through iconic imagery, as Native American.

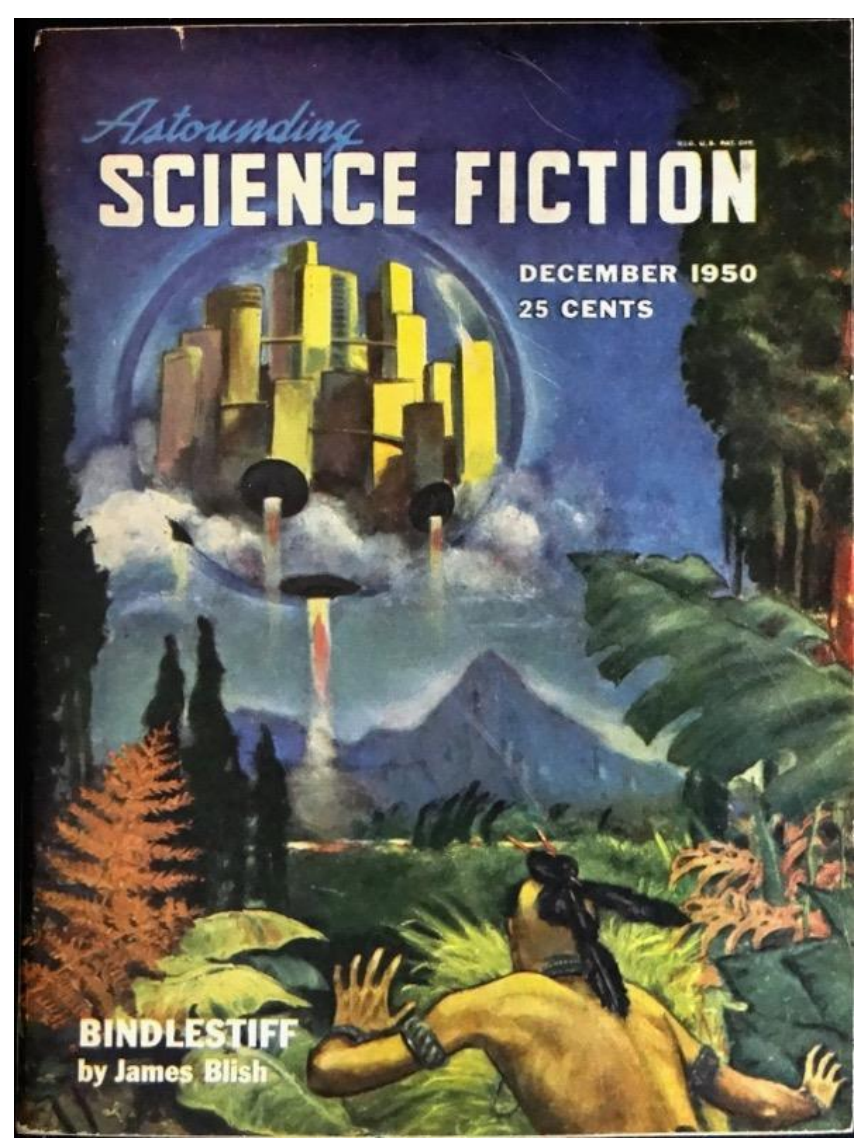

Figure 1. Astounding Science Fiction, Dec. 1950.
For the purpose of this investigation, I employed mixed digital and traditional humanities methods to identify and describe cover images of science fiction that portray cities, or city-like structures, in tropical settings. A starting point was to consider how the people and cities of the tropics could be identified from science fiction cover art, and how this might reflect the cultural environment of the specific period of these covers being produced, or if these representations were symptomatic of more enduring cultural expectations of the tropics.

A mixed methods approach was called for. To apply only digital methods would be to ignore the richness of the reflective experience of the researcher. As emphasised by Katie Trumpener, there is a need for such approaches to focus not only on statistical and other forms of digital-only analysis, but to respect the pheonomenological experience through "browsing in addition to quantification; incessant rather than distant reading" (Trumpener, 2009, p. 171). Julia Flanders has described the role of literature researchers employing digital tools as being one of mediation between the process and the field of enquiry (Flanders, 2013). For those focused on purely technological approaches to analysis, Tanya Clement has observed that the self-reflection of the researcher, based in their own phenomenological bracket, is a "technology" of and in itself (Clement, 2013, p. 2). As our research outputs demand human understandings and comprehension, it is 
evident that it is necessary to blend the human and digital processes to generate meaning, and the methodology applied here makes use of the 'wetware' technology of the human researcher, as well as computer software.

The application of digital tools is valuable in highlighting and controlling the influence of our phenomenological bracketing of our work, but also enables us to reflect on, and gather insights, regarding the sources of that bracket - and how they might be derived from social and cultural constructs which we might not otherwise consider. In this research, this led to a gestalt continuation from 'the tropics' as 'Earthly' to the implications of viewing the tropics from a (literally) alien perspective, which might provide a fruitful line of enquiry for further research.

\section{Magazines and Cover Art}

The corpus of literature examined for this research paper comprises twentieth century magazines and books dating from the origins of 'pulp' science fiction in the 1920s. Science fiction is a valuable field for thought experiments on culture and society as it is an 'open' literature - one that embraces a range of topics and content that is not limited by genre conventions, and may offer provocative insights into the contemporary world view. Magazine fiction is rapidly produced and this contemporizes the content - as Michael Ashley has commented in his compendium The Age of Storytellers: 'given the relatively long production time of the book, the magazine was the more immediate and "newsworthy', and has an 'immediacy and cheapness' (Ashley, 2006, p. 3) that can generate a significant audience. The generalisation of results from science fiction research has been problematic in the past, when the demographics of readers was biased towards a young male audience. This has changed as the demographic profile of the science fiction audience has trended over the last half century towards that of the host population (Menadue \& Jacups, 2018), making the magazines increasingly valuable as indicators of the cultural zeitgeist.

It is perhaps impossible to over-emphasise the role of cover art in defining and marketing magazines - as both an indicator of content and a means of attracting attention, and readers. It follows that cover art must conform to the expectations of its time. Ashley provides examples of how cover art changes to reflect cultural transformations, such as the phenomena of rapid societal and technological change in the 1920s (2006, pp. 51, 110), and also provides numerous examples which highlight the sustained correlation between content and covers of magazines: 'Adventure, mystery and humour dominated Pearson's, and is the image that its covers projected' (2006, p.167), when Pearson's changed its content, its covers changed to reflect this: 'The covers became light-hearted sketches....and the humour section was expanded' (2006, p.168). Ashley also describes how Tip Top 'promoted 
itself as a magazine of "adventure and mystery", a fact evident from its action covers' (2006, p.211), and he implies the fortunes of magazines were significantly linked to the cover art: 'when Tip Top was rebranded as Regent Magazine in 1924, 'the covers became softer, depicting scenes of leisure and romance rather than adventure. The result was astonishing...the first new issue sold out within three days' (2006, p.211). A lack of correlation between cover and content can be damaging, however, and it is necessary for the art to meet the expectations of readers. Empire Frontier magazine became 'no longer representative of its title or cover', which caused it to 'become confusing' for the reader (2006, p. 69), and the 'bland white covers' of The White magazine 'may not have helped, but the magazine lacked verve and with more exciting material around The White Magazine faded to grey' (2006, p.222). Cassell's was rebranded as Cassell's Family Magazine and 'with dull lifeless covers, sank into mediocrity' (2006, p.53). In the case of The Grand, 'a series of lacklustre covers harmed the magazine's image, though it restored stronger action covers in 1937.' Ashley highlights cover art as a significant dynamic for Mystery-Story: 'Not only were the stories as atmospheric and sensational as possible, but so were the covers. Bright, gaudy and full of action' (2006, p.128). Ashley also variously describes how covers of successful magazines were attractive (2006, pp. 45, 49, 114, 122, 139, 169), and correlated with success (2006, pp. 53, 85, 122, 204), and cover art became collectable (2006, pp.44, 131).

Science fiction is commonly used in a research context, and is significant in this regard as a literature that is widespread in the popular imagination (Menadue \& Cheer, 2017). The popular definition and comprehension of science fiction, however, is extremely homogenous and based on the significance of technology and plausibility rather than more esoteric distinctions made by literary theorists (Menadue, Giselsson, \& Guez, 2018), and this consistency makes the visible changes in content and art more worthy of note than if the popular understanding of the genre was less clear. Consequently, examination of imagery found as science fiction cover art was considered to be a suitable method for exploring the changing cultural perceptions of the tropical, and is an extension of previous work on the representations of the tropics in narratives found between the covers of these magazines (Menadue, 2017).

\section{Methods}

The methodology employed is 'proximal reading' (Menadue, 2018b), which reduces the influence of researcher selection bias by applying digital methods to selecting relevant material from a larger corpus. This lays the foundation for a more phenomenological process of exploration. A rule-based, rather than experience-based approach to selection of sources, may discover new or divergent material that might otherwise be overlooked. 
A review of the literature follows a structured process that employs digital assistance to identify content or phenomena relevant to the research theme. The phenomenological experience of the researcher is integrated by a semi-structured pathway that directs the focus by employing boundary conditions - these are 'degrees of separation' and 'the random walk.' Frigyes Karinthy proposed in The Chain (Karinthy, 2011) that any two individuals in the world could be connected by at most six links made between other people, and was the originator of what is now a wellknown concept. The random walk (Pearson, 1905) is an observation of patterns created by a succession of seemingly random connections. This is analogous to conscious, intuitive, or even genuinely random, associations we make, born out of experience and curiosity, that discover additional information about the sources we investigate. The degrees of separation allowed between the sources we have identified in the first stage, and the furthest link away from that source, can be decided at the outset. ${ }^{1}$ The associations between sources initially identified with relatively objective digital assistance may appear random to an external observer, but the links between them arise from applied phenomenological experience and expertise - the technology of the researcher, as Clement has suggested (2013). The degrees of separation applicable to define the boundaries of any unique application of these methods are limited by the time and resources available to read and assess the findings. This scales according to the scope of investigation - the present undertaking assessed thousands of cover images, and time did not permit additional degrees of separation in this instance beyond a cursory one-degree investigation of the content of issues that featured women in a tropical environment - these demanded further investigation to clarity the context.

The PRISMA methodology (Liberati A, 2009; Stevens et al., 2014) was used to structure the selection of covers from an extensive catalogue of 5,705 individual images (Figure 2), and ImageSorter (Barthel, 2007) was employed to enable this. ImageSorter creates scalable thumbnail images of folder contents, and enables sorting by colour - which is not a feature commonly found in other applications. ImageSorter also reads the first page of a PDF as an image, so laborious extraction of cover images from PDF format archives is not required. Colour sorting offers a method for rapidly filtering images likely to be irrelevant - those that are predominantly black or very dark may indicate scenes in space; white may depict arctic images, and

\footnotetext{
${ }^{1}$ As an example of prior art, a review of Satan's Slaves in the Anglo-Australian counter-culture magazine Oz in 1971 (Neville, 1971) referred to claims made that Charles Manson was interested in Scientology, this was linked to a rebuttal notice by the Church of Scientology both in that publication and in a separate review of Satan's Slaves in a science fiction magazine this describes a three-degree separation from the finding of a first rebuttal letter in the December 1970 edition of Fantastic magazine (Deckard, 1970, p. 129; Menadue, 2018a, 2018b).
} 
these can be immediately rejected. Images that are predominantly green, yellow or red in colour may depict jungles or deserts. Initial screening identified duplicate images, this was followed by colour sorting. The 638 images remaining were screened by examining batches of larger thumbnails, and final selection was based on closer inspection of potentially relevant images.

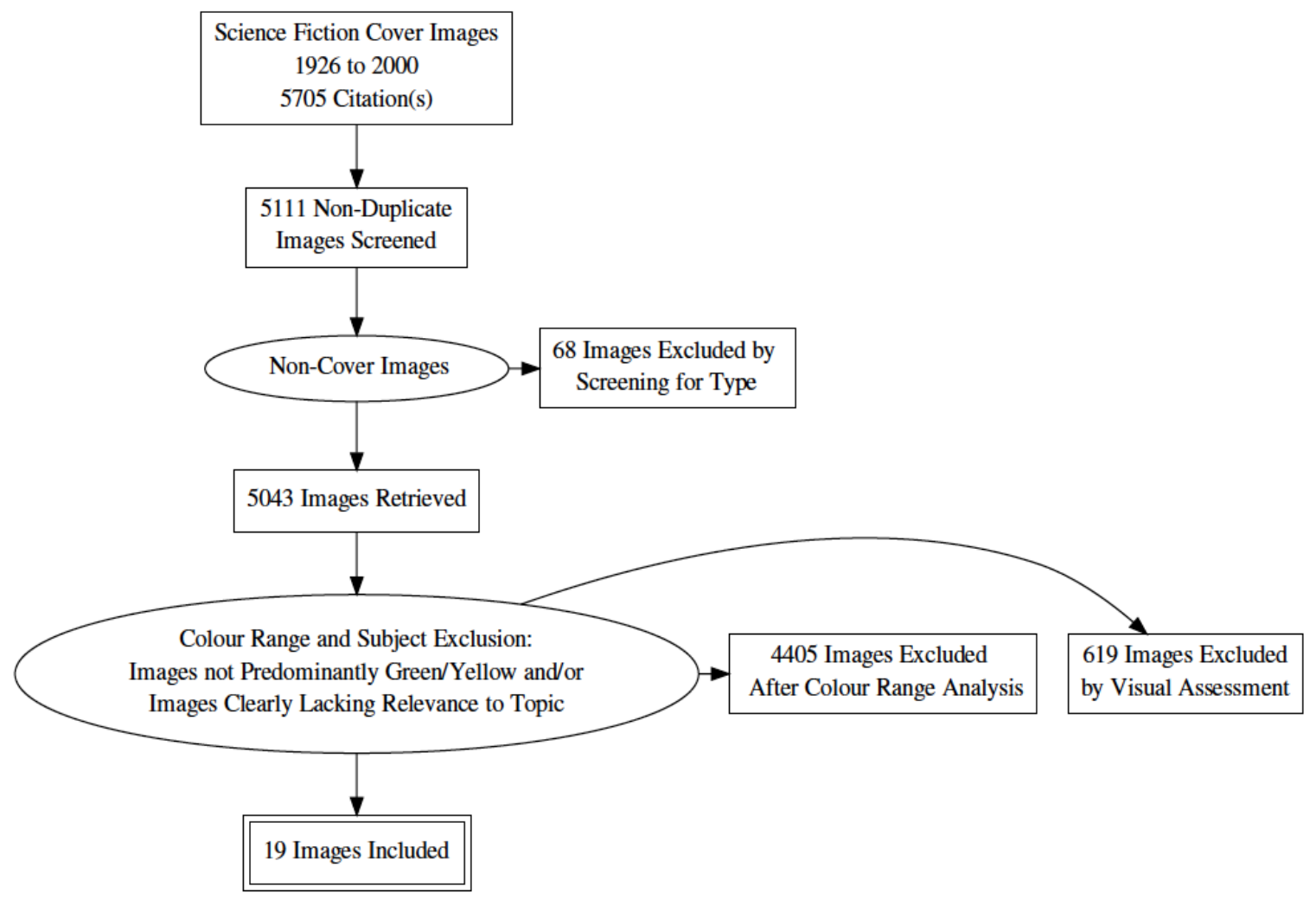

Figure 2. PRISMA diagram of systematic image selection process.

\section{Findings and Discussion}

The covers selected featured humans, indigenous peoples, either humanoid or alien, city-spaceships, ruins, jungles and deserts. Attitudes of protagonists were generally warlike, but neutral or even peaceful situations were also depicted. The scenes portrayed can be categorised into various science fiction tropes and traditions, and changes in the conception of these are apparent over time. There are, however, some general assumptions made regarding the characteristics of indigenous inhabitants of tropical cultures, and particularly wet tropical cultures. Representations of tropical indigenous peoples (human or otherwise) employ iconography that implies a comparatively less civilised and less technologically advanced culture than that of the non-indigenous explorers and colonists who enter, or invade, their territory. 


\section{The Tropics}

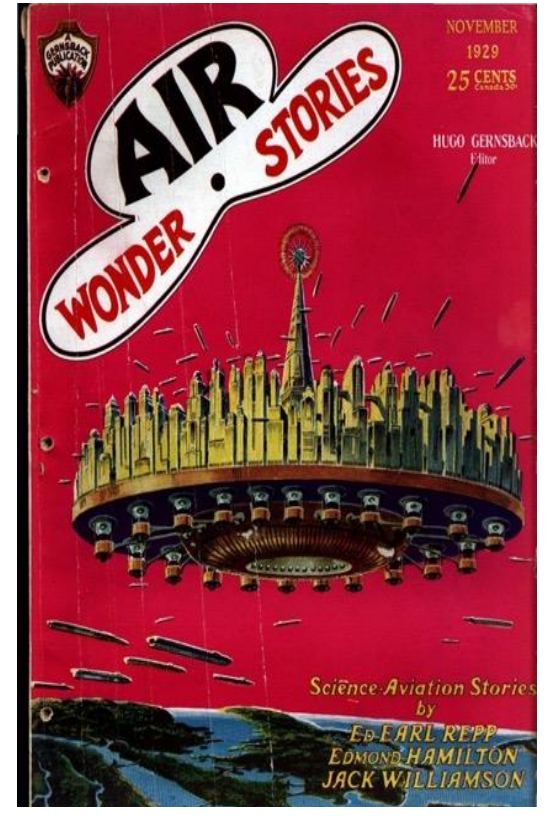

Figure 3. The evolution of the flying cities of science fiction. Air Wonder Stories, Nov. 1929

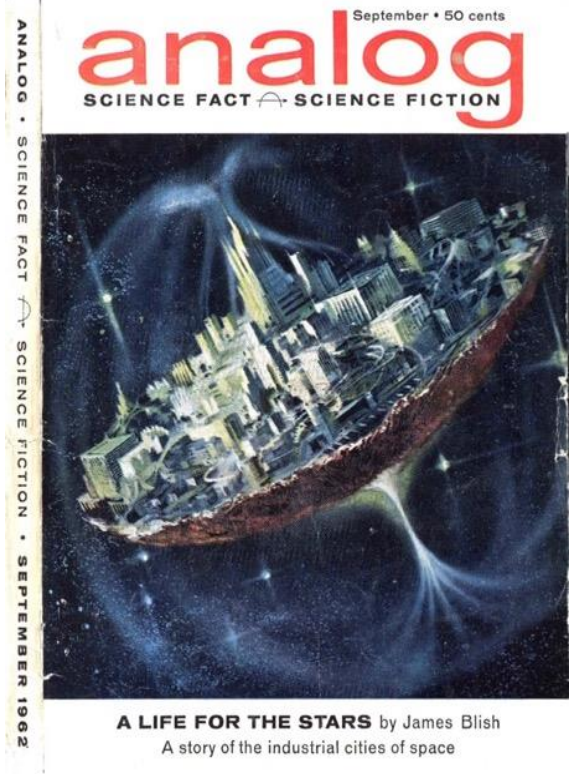

Figure 4. Analog Science Fact Science Fiction, Sep. 1962

The unlimited opportunities for presenting worlds and situations afforded by science fiction, made it apparent at an early stage that a measure of equivalence to the Earthly 'tropical zone' with which we are familiar needed to be made. Inclusion rules needed to be defined and applied. These were based on iconic human conceptions of tropical environmental conditions and typology that might be expected in Aristotle's 'torrid zone' (Meteorology, 362a31-363a20). After images of planets incapable of sustaining life without protection were excluded, jungle scenes were identified by jungle plants and dense plant life and/or the lack of need for protective (or any) clothing on the part of the inhabitants, desert scenes had to be assessed for temperature, based on the apparent need for protective clothing. It was considered appropriate to attempt to assess environmental conditions from the experience of the indigenous peoples, and in some instances conditions that appeared 'hot' for the locals required considerably more protection for human visitors (Figs. 10,11,12). Sometimes, however, this might have been a choice on the part of the artist, made with less consideration for environmental accuracy than aesthetic considerations of another sort.

The relatively few inhabitants portrayed, especially in vast, open, desert landscapes, might imply, as Veronica Davidov suggests, that 'the indigenous savages were/are inscribed into a narrative of fascination with the unknown frontier wilderness, in which the imagined mysteries of the pristine [tropical] forests are projected onto their 
inhabitants' (Davidov, 2011, p. 471). She argues this may be based on 'fantasies of deterritorialised "wilderness"' (2011, p. 472), and thus may be a form of "imperialist nostalgia" (Rosaldo, 1989, p. 69). The general lack of depictions of sophisticated indigenous technology may be inspired by what Davidov describes as "perfectly pastoral geography...metonymically dependent upon the absence of technology, effectively splitting the "wired" modern contingent of the population from the preindustrial ecotopia' (2011, pp. 481-482) This contrast enables the readers to command an immediate grasp of the situations depicted: the cover representations being 'cultural shorthand' for a range of tropical scenarios.

\section{The Tropical City}

A novel consideration of science fiction is what constitutes a 'tropical city' in this setting. Cities themselves are not exclusively definable by traditional 'bricks and mortar' conceptions. A variety of structures might have the same function - orbital habitations, generational spaceships, and even a digital cloud of transhuman minds as exemplified in the works of William Gibson, Vernor Vinge and Hannu Rajaniemi (Gibson, 1984; Rajaniemi, 2010; Vinge, 1992). The author James Blish is known for his series of short stories that were later published as Cities in Flight (Blish, 1971). The Astounding Science Fiction cover for December 1950 (Fig.1) illustrates the earliest of these stories, and the trope of the flying city-spaceship is commonly found in science fiction (Figs. 3-4), and Blish later continued this theme (Fig. 4). In Blish's narratives, the 'city in flight' is an escapist/adventurous post-colonial trope associated with encountering indigenous cultures, and it became apparent during the filtering process that the concept of a 'city' in a science fiction context is richly variable, and not dependent on fixed infrastructure. Giant spacecraft were therefore included as a form of science fiction 'city' (Figs. 5, 10, 14, 17-19), not unlike the 'cities' of American aircraft carriers, which may have 6,000 crew (Naval Technology, 2018), but on an even larger scale considering the huge resources required for interstellar journeys, and the necessity to support generational populations. This 'mobile city' suggests a colonial mythology overlies representations of city-structures in alien settings, and those in tropical settings may be informed by the history of western colonisation. Interestingly, the city is most often seen from the outside and from afar, as an imposing feature of the landscape, or an illustration of the source of origin of the visitors. Only one scene shows the inside of a city (Fig. 12), and one other (Fig. 7), appears to be in 
the liminal space between city and the surrounding region. If we consider that in the history of European exploration of the Earth, ships set out with instructions to not only discover, but to claim new lands, then we might interpret giant spaceships similarly the harbingers of a colonial culture, prefabricated cities, rather than merely transport for curious travelers. A characteristic of these fictional city-structures is the normative expectation inherent in the artwork that the inhabitants are civilised and technologically advanced, whereas the people of the tropics outside are primitive and lack advanced technology. This simple dichotomy is visible in the greater majority of the covers identified.

\section{Indigenous Peoples}

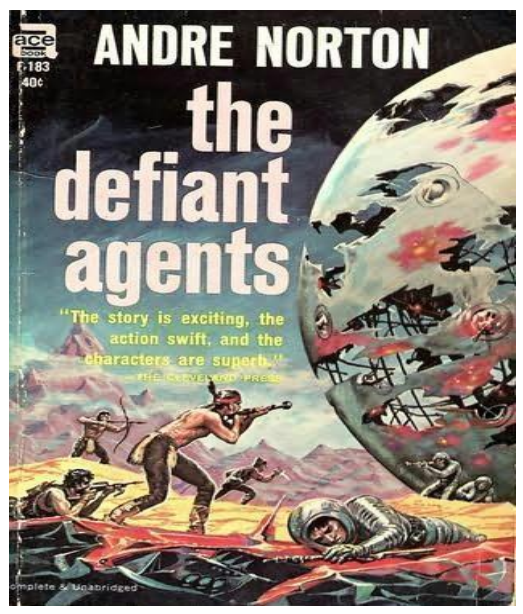

Figure 5. The Defiant Agents, by A. Norton, 1963.

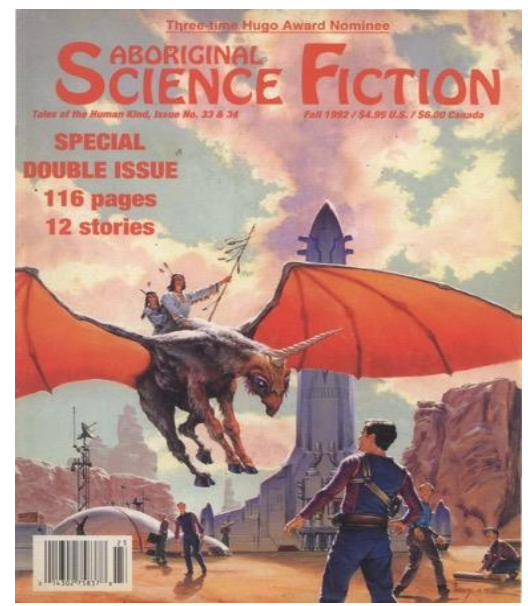

Figure 7. Aboriginal Science Fiction, Fall 1992.

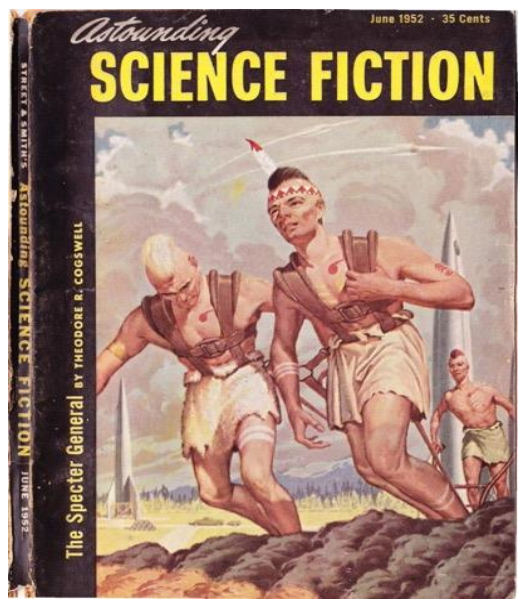

Figure 6. Astounding Science Fiction, June 1952.

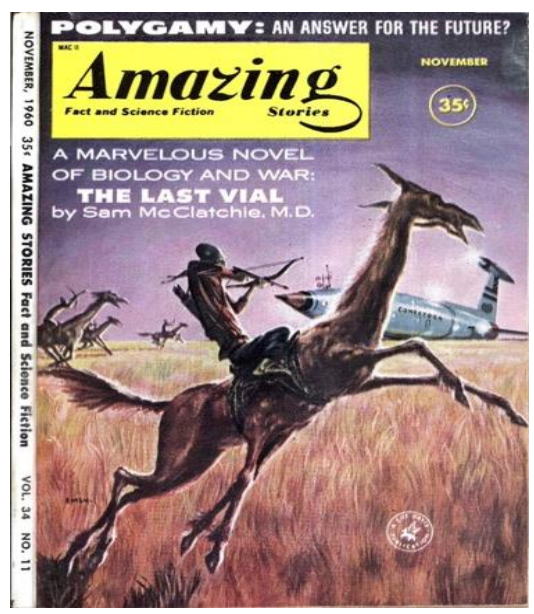

Figure 8. Amazing Stories, Nov. 1960. 
Indigenous inhabitants of tropical zones usually appear less technologically advanced, and less civilised, than other-worldly visitors. This becomes less binary as the century advances, and power relationships displayed between indigenous and non-indigenous participants become more neutral in later work (Fig. 7), but some tropes are persistent. Humanoid indigenous peoples in American publications exhibiting low technology or lack of cultural evolution are often associated with Native American iconography (Fig. 6, Fig. 7, Fig. 8). This is rarer in British magazines. Ashley has commented on how a Native American did appear on a cover of The Golden Mag. in a story of conflict between Native Americans and white settlers (Ashley, 2006, p. 80). The association of violence and primitivism with Native Americans is embedded in American culture. Jodi Byrd states in Living My Native Life Deadly: 'The possibility of an eruption of unanticipated Indian violence and the expectation of the hostile Indian savage seeking revenge for historical crimes remain a powerful threat within non-Indian imaginings' (Byrd, 2007, p. 316), and Native Americans typify a romanticized, low technology, culture: 'the juxtaposition between the break-down of modernism's logics... and the romantic nineteenth-century images of Indian guides only reifies the exclusion of Indians from the processes of modernization' (2007, p.317). Arrows and pow wows are nineteenth-century indicators that continue to resonate (2007, p.318), and the trope 'evokes a much simpler time of wild-life and frontier' (2007, p.318). As Reginald Horsman writes in Race and Manifest Destiny the accepted scientific stance in the mid nineteenth-century was that 'the Indians were doomed because of innate inferiority, that they were succumbing to a superior race, and that this was for the good of America and the world' (Horseman, 1986, p. 191). This colonial expectation is found in early science fiction covers depicting Native Americans, sterotyped by dress, violent attitudes and lack of technology, justifying colonial exploitation. Chad Barbour develops this concept further: 'the "vanishing" Indian willingly releases his land and bestows his authentic "Americanness" upon the advancing "new" Americans. And along with that transmission of land and identity, the Indian also provides an admirable model of manliness for white males' (Barbour, 2015, p. 279). This combination of 'noble savage' and 'doomed civilisation' is prevalent in American cultural representations of the Indian, as Philip Deloria says: 'Savage Indians served Americans as oppositional figures against whom one might imagine a civilized national Self. Coded as freedom, however, wild Indianness proved equally attractive, setting up a 'have-the-cake-and-eat-it-too' dialectic of simultaneous desire and repulsion' (Deloria, 1998, p. 3).

In the science fiction genre, the Native American serves as a shorthand for a culture that is rugged and masculine, which provides worthy adversaries, but which cannot, and should not, stand in the way of technological progress and colonial strategies. As iconography, the Native American is very readily identified, and as the visual indicators are part of a white imagining, Richard Slotkin argues that these indicators 'extract Indianness from the Indian' (Slotkin, 1973, p. 357), Barbour states that this 'process 
of appropriation...preserves the former [Indianness] in visual signs and material objects while the latter [the Indian] is abandoned and marginalised' (2015, p. 270). The depiction of Native Americans is both value-laden, and surface - without any realistic understanding of 'the Indian' required or requested. Barbour further suggests: 'Indianness is multivalent tablet upon which white culture inscribes its ideals and fears' (2015, p. 270). It follows that in American science fiction adventures the Native American trope provides excellent material for depicting generic primitives, as it has been reduced to iconography in American culture - 'the power of Indianess lies in its divorce from actual Indigenous peoples' (2015, p. 270) - without a definite sense of origin of place or cultural embodiment. Notably, Native American iconography features more prominently on thrdr magazine covers than that of other cultural stereotypes. No Asians are implied on these covers, which is surprising as the use of Asian characteristics to portray aliens has been described as a common feature of science fiction between the world wars (Cheng, 2012, pp. 148-149). This may be a statistical artefact of the relatively small number of tropical environments that were identified by the search, or an indicator that in science fiction the Native American provides more readily digested material.

\section{Representations of Women}

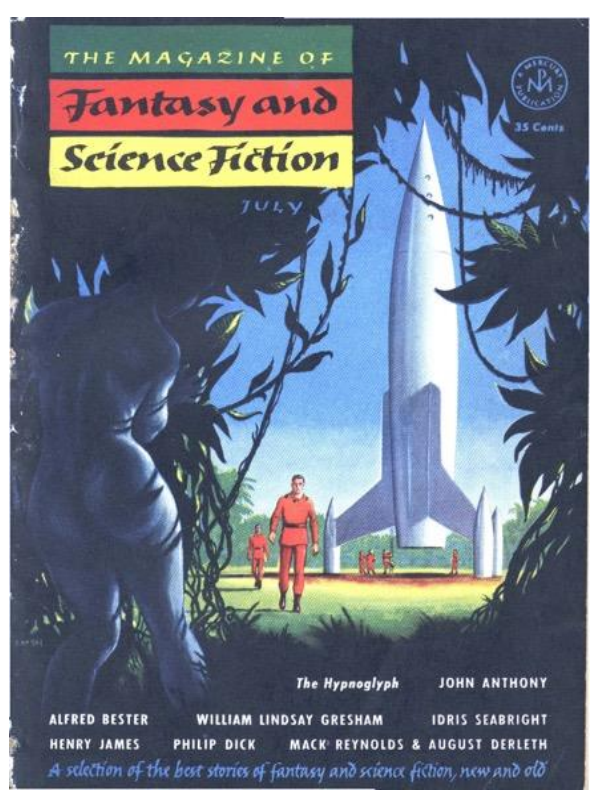

Figure 9. Amazing Stories, by J. Lalt \& L. Mortimer, Jul. 1953.

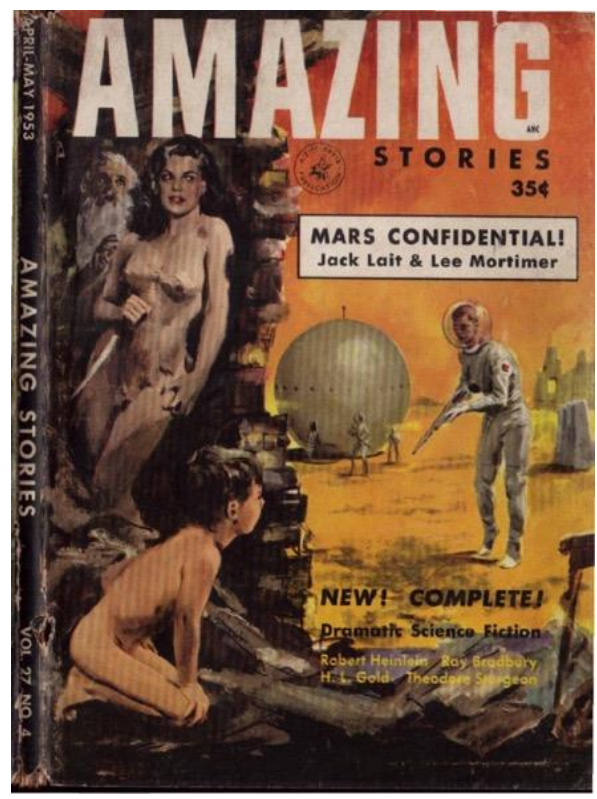

Figure 10. The Magazine of Fantasy and Science Fiction, Apr./May 1953.

Sexualised portrayals of naked or semi-naked women are a standard feature of the cover art (Figs. 9-12) - perhaps artists excused this on account of 'tropical' settings. 
Women become slightly more sensibly dressed over time, but still gratuitously depicted (Figs. 11-12). Women are less frequently found on more recent covers, and their depiction tends towards a higher degree of sophistication, even if they are still not portrayed from a neutral perspective (Fig. 12). The portrayal of gender is a simple binary, and the only clearly female representations are of humans. A brief inspection of the story content relating to women in these environments finds simple, traditional, tropes - women as Amazon warriors, and willingly submissive to the advances of male explorers. The only powerful female character is in The Wizard of Anharite, from Worlds of If (Fig. 12), but she is described as a science fictional witch, another traditional female stereotype.

Changes in the portrayal of the female to meet cultural expectations have been described in non-science fiction magazines, with stronger representations featured in or around the 1920s. During 1922 Premier magazine 'changed to portraying women rather than depicting scenes from stories' (Ashley, 2006, p. 172). In The Yellow covers changed in 1926 'to present a stronger image of women's stories' (2006, p.238), and for The Novel in April 1919 'The cover reflected female liberation with a woman aeronaut, and over the next year most covers portrayed women in new guises. The feminist angle was strong' (2006, p. 145).

\section{The Tropical 'Native Belle'}

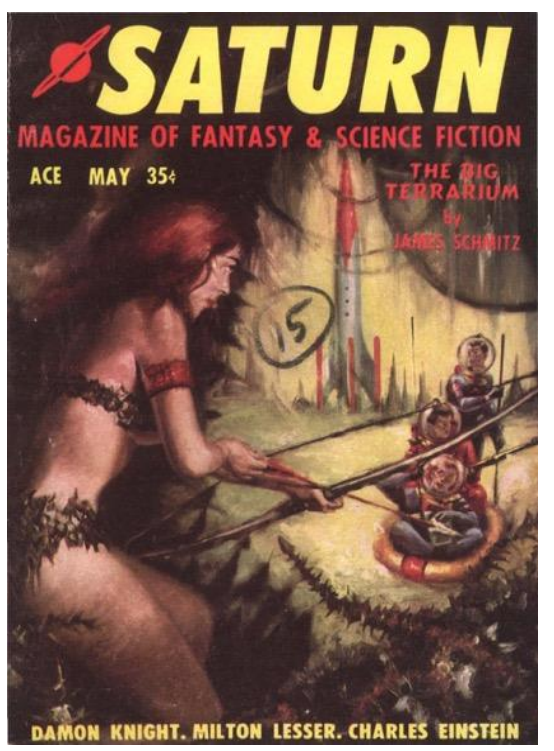

Figure 11. Saturn, May 1957.

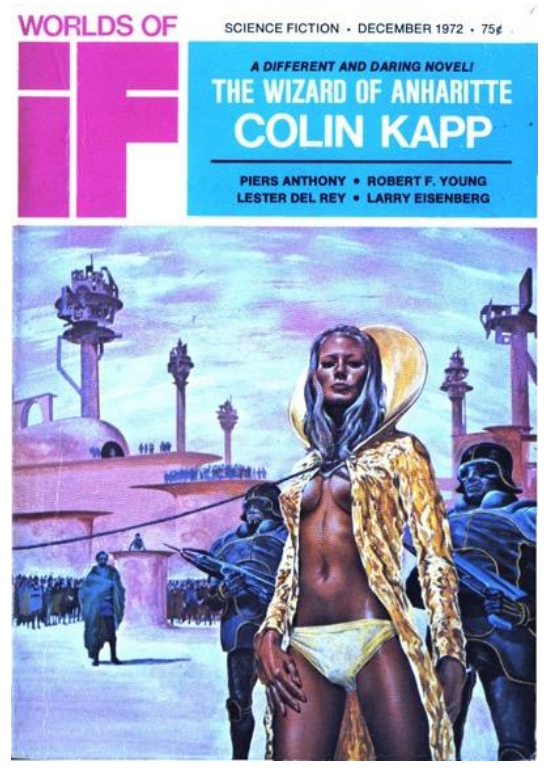

Figure 12. Worlds of IF, Dec.1972. 
The contrast between salacious portrayals of women and scenes of violent conflict may reflect what Veronica Davidov describes as 'the positive and negative qualities Europeans projected onto their colonised subjects, distinguishing between "hard" primitivism, which imagined the "primitive" subject as courageous and brave in the face of the hardships inherent in their "wild" lifestyle, and "soft" primitivism which saw them as languid and sensual, harmonious, and one with their natural surroundings' (Davidov, 2011, p. 469). Liz Conor has described the representations of Indigenous women in material culture in the context of Australian exploration and settlement by Europeans, determining that 'feminine beauty would become a defining discourse of racial difference between 'civilised' and 'primitive' women' (Conor, 2006, p. 197). Chad Barbour remarks: 'The physical body exposed in this way also marks a certain primitiveness or savagery (clothing, or lack of, long being associated with the perception of civilisation)' (Barbour, 2015, p. 278). The lack of any evident embarrassment, regardless of scant clothing, suggests Conor's 'native belle,' who is 'unselfconsciously beautiful: hers was not a beauty of artifice; it was not therefore modern' (2006, p.198). Conor remarks that observational technology, such as printing and photography, enabled dissemination to a European audience that 'shaped the lens through which Indigenous women were seen and perceived as racially different.... The depictions of the manners and customs of the native woman was intensely focused on their visual effects' (2006, p.202). This tradition of remote aesthetic appreciation of the tropical woman appears to linger on science fiction covers. Conor observes that nineteenth-century explorer Edward John Eyre 'proposes an improvement on the native - the hair is 'purified' - thus redeeming a beauty that is marred or defaced, or which Aborigines are incapable of appreciating themselves' (2006, p. 206). The white explorer controls notions of beauty - and interactions between science fiction explorers and their 'native belles' are imbued with this notion - that a 'redemptive colonial gaze beautified the unwitting native belle' (2006, p. 213). Conor notes: 'An 'immoderate fondness' for Indigenous beauty was the 'passion' of colonials, who 'extended the dominion of mind' over Indigenous women's bodies, shaping the conventions of representing those bodies as docile to colonialism' (2006, p. 213). This is perhaps more obvious in narrative content of magazines which 'always resolved in favour of good, rightful and civilised protagonists' (Menadue, 2017, p. 138) than on the covers; but power relationships are clearly indicated by the fact that the 'native belles' remain in concealment (Figs. 9-11), or are captive (Fig. 12). 


\section{Representations of the Attitudes of Tropical Peoples}

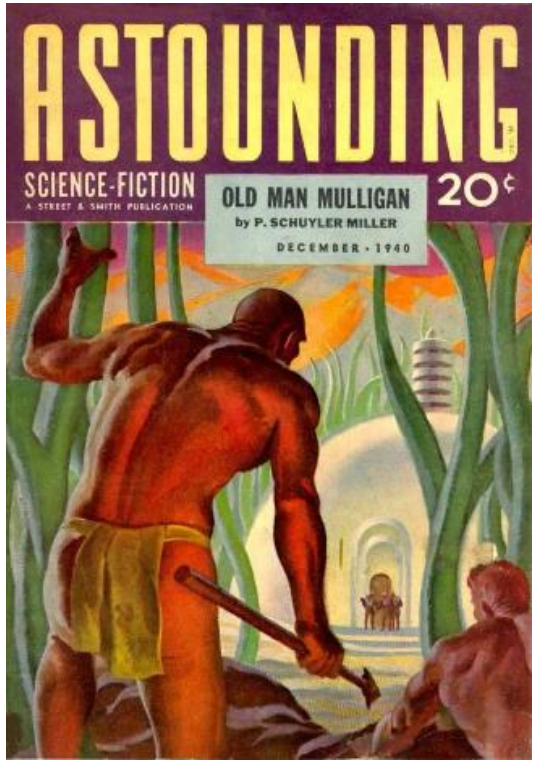

Figure 13. Astounding Science Fiction, Dec. 1940.

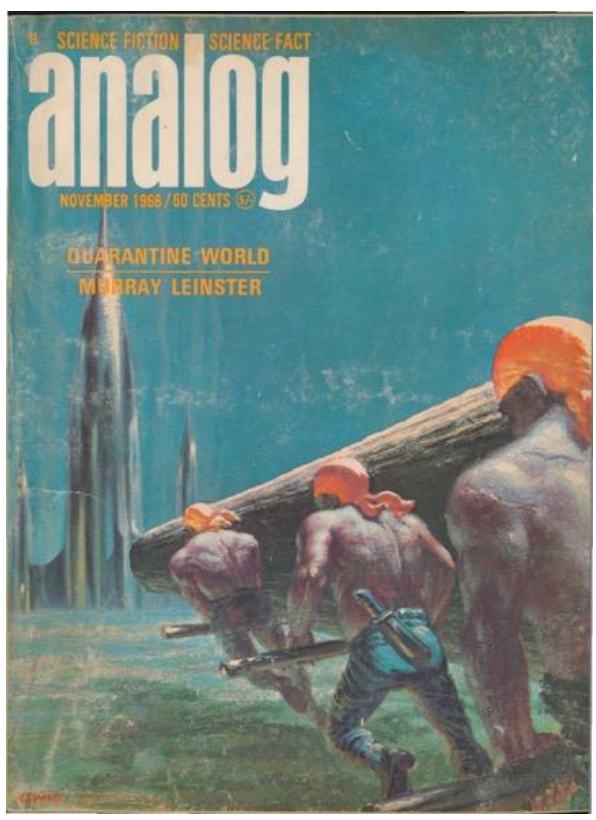

Figure 15. Analog Science Fiction Science Fact, Nov. 1966.

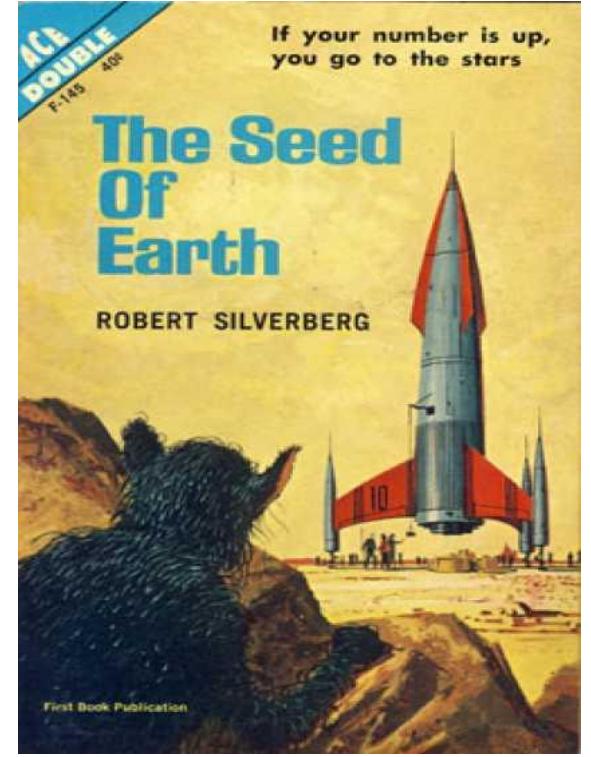

Figure 14. The Seed of Earth, 1962.

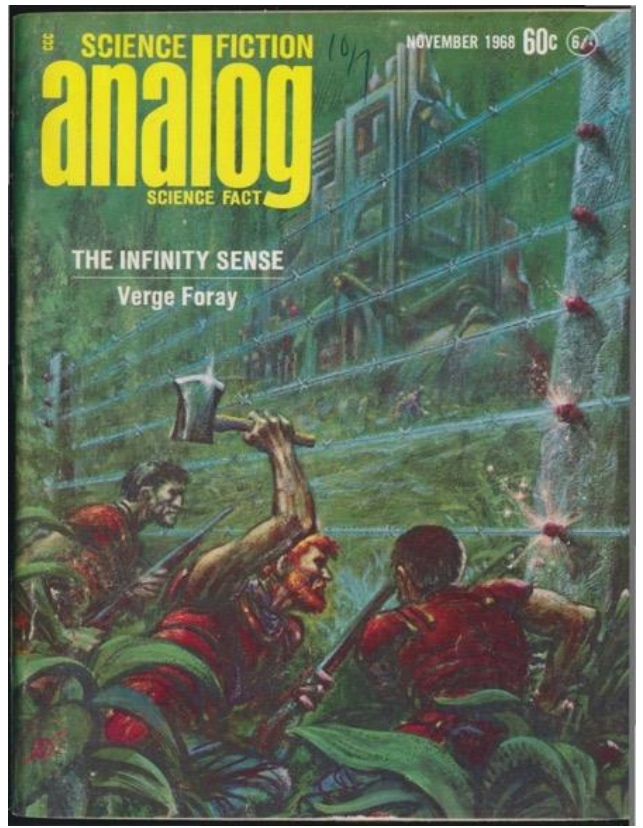

Figure 16. Analog Science Fiction Science Fact, Nov. 1968.

Neutral observers feature on some covers, with no clearly hostile intent. These are universally portrayed from the perspective of the Indigenous characters, and may imply wariness (Figs. 9, 11, 13-14) or surprise (Fig. 1). Far more common are images of direct conflict between Indigenous peoples and outsiders, whether humanoid or 
alien species (Figs. 5, 8, 9, 11, 15-16). Individuals are almost universally found bearing arms of various degrees of sophistication; from spears, axes and bows to futuristic weapons. There are situations in which Indigenous people are openly hostile (Figs. 7, $9-10,12,15-16)$. Tropical inhabitants are armed with weapons indicating low technology - bows, axes, knives, spears, blowpipes, even a battering ram (Fig. 15). This implies tropical cultures are primitive and warlike, a myth perpetuated in the interests of colonial settlement on Earth - here generally analogous to the exploration and exploitation of the Americas, implied by the Native American trope discussed above.

\section{Dereliction and Lost Civilisations}

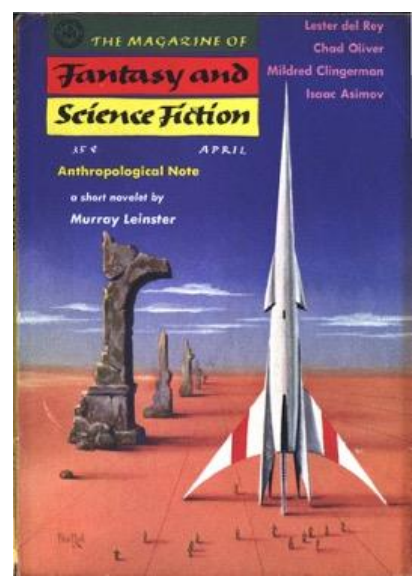

Figure 17. The Magazine of Fantasy and Science Fiction, Apr. 1957.

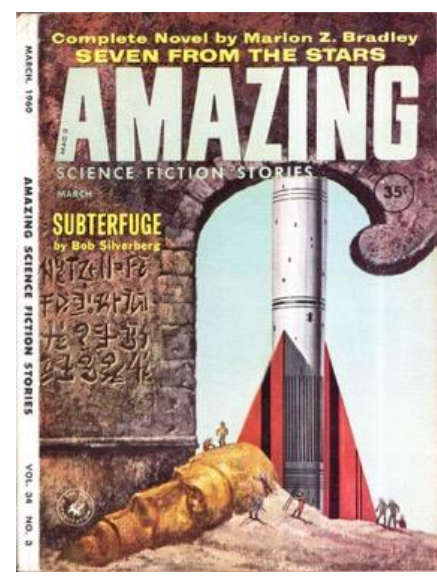

Figure 18. Amazing Stories, Mar. 1960.

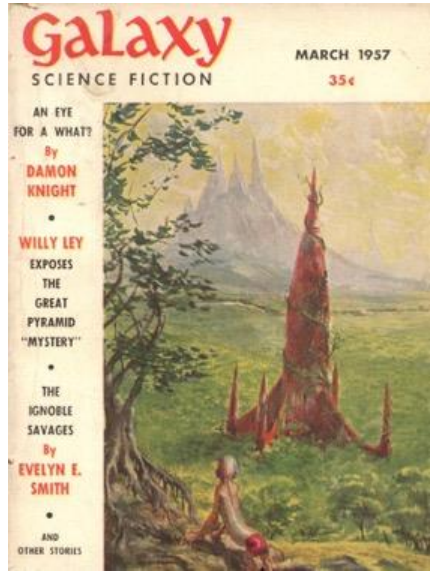

Figure 19. Galaxy Science Fiction, Mar. 1957

Three covers portrayed archaeological sites - rockets visiting the remains of imaginary alien cities (Figs. 17-19), and a gigantic derelict spaceship in an alien landscape (Fig. 19) - a reversal of the explorer-conqueror trope. The discovery of remains of lost civilisations, and ones that suggest significant technology, is redolent of the European history of exploration of non-European cultures, the discovery of 'lost civilisations' and romantic idealization of archaic culture. This comes with the rejection of contemporary inhabitants as living manifestations of the continuation of those cultures, and implies that the region is now uncivilized: culture no longer exists.

This feeds the argument of 'Terra Nullius' in a cultural context - that the recent inhabitants are not the original owners or inheritors of the land, and therefore can be exploited or supplanted, exemplified by the colonisation of South-East Asia by the French, British, Dutch and Portuguese, South America by the Spanish and Portuguese 
and Africa by a variety of European countries, and, of course, the British colonisation of Australia.

\section{Tropical Culture}

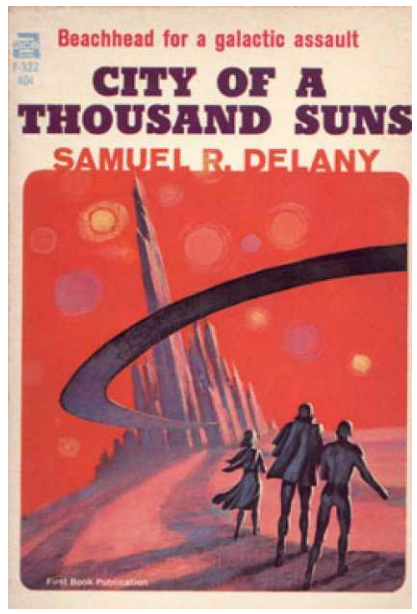

Figure 20. City of a Thousand Suns, by S. R. Delany, 1965.

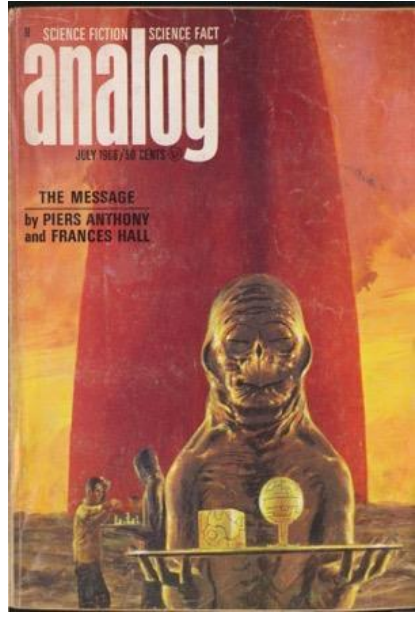

Figure 21. Analog Science Fiction Science Fact, Jul. 1966.

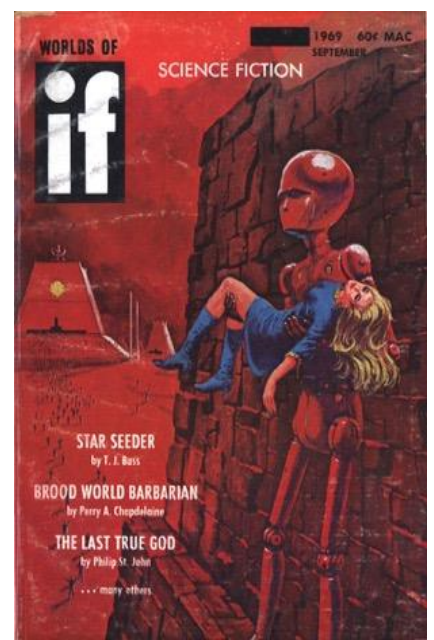

Figure 22. Worlds of IF, Sep. 1969.

The complexity of the tropical environment and the range of imagery became more diverse and sophisticated over time. This supports previous work which has indicated changing concepts of the tropical environment in the content of science fiction magazines (Menadue, 2017). A feature of city-like structures is a scale beyond what might be considered the 'space tourism' of exploratory science fiction tropes. Implications of colonisation, control and conflict directed towards Indigenous peoples is frequently seen meeting violent opposition. The 'watchers' might have been depicted as wary due to the association in popular culture, and science fiction narratives, of advanced technological civilisations encountering less resource-focused cultures with the intention of domination and exploitation. Neutral and more positive imagery appears when equality between Indigenous and non-indigenous people is portrayed (Fig. 7, Fig. 18), or civilisations appear to be extinct (Figs. 20-21). 


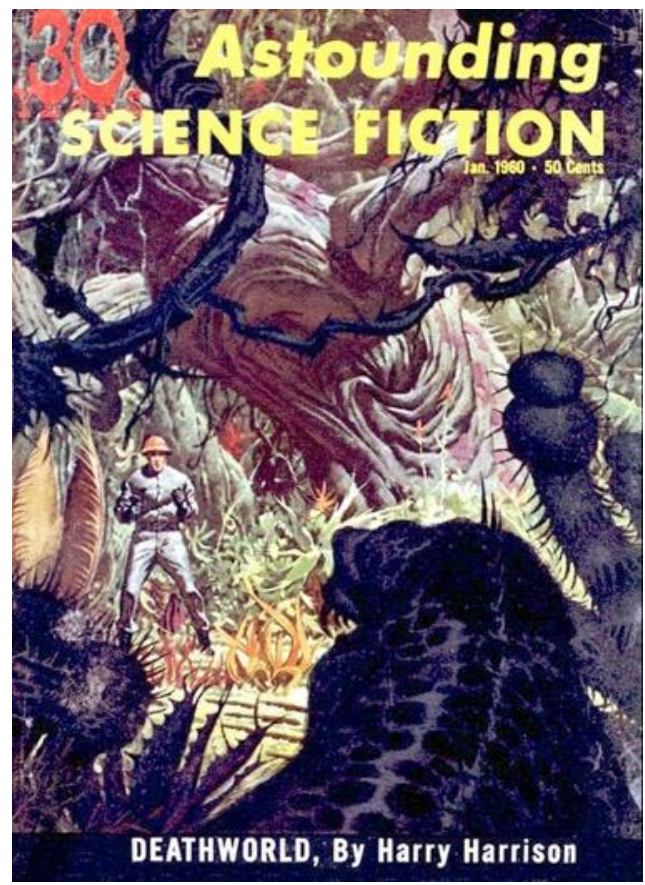

Figure 23. Astounding Science Fiction, Jan. 1960.

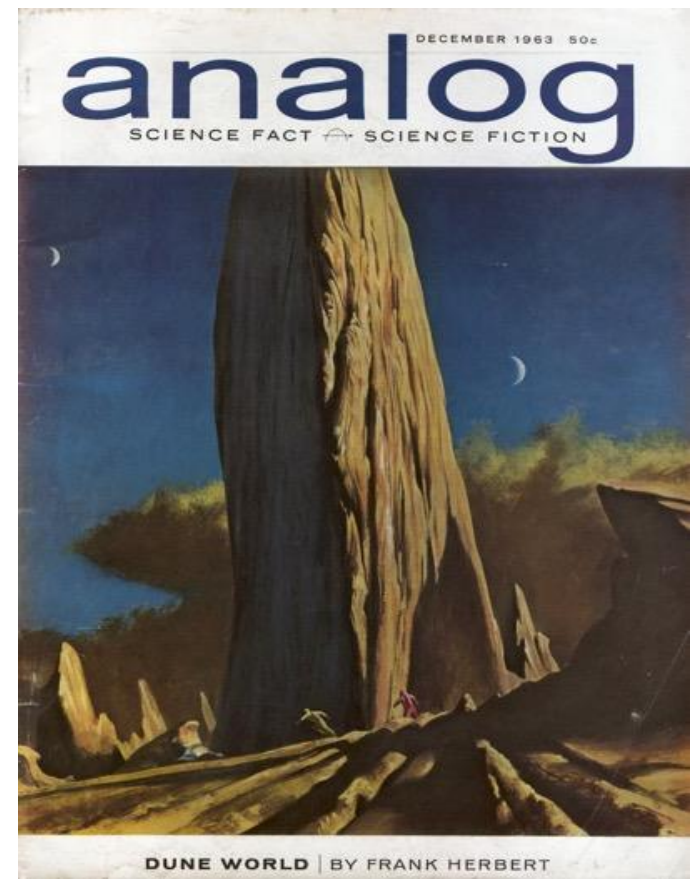

Figure 24. Analog, Sep. 1963. Cover for Frank Herbert's Dune World. By John Schoenherr

Indigenous civilisations portrayed in desert environments (Figs. 7, 12, 17-8, 20-22) are generally more sophisticated than those of the wet tropics (Figs. 1, 10, 11, 13, 16). This portrayal of the 'uncivilized' wet tropics compared to the 'civilised' dry tropics is consistent with other portrayals of tropical and desert environments in science fiction cover art. Examples of this cultural distinction would be Deathworld by Harry Harrison (Fig. 23), compared to Dune World by Frank Herbert (Fig. 24) - both originally published in magazines. Deathworld portrays a hostile tropical world where settlers discover the jungle environment contains plants and animals whose only apparent motivation is to exterminate humans. In Dune, by comparison, the ascetic, sophisticated, and violent, desert culture of the Fremen nomads (closely modeled on Herbert's conception of Arabic cultures) triumphs over and supplants a decadent imperial culture, which at the beginning of the story is the dominant force in the galaxy. The heroic protagonists of Dune are "the "good savage" that is a prominent archetype in the symbolic universe of postcolonial environmentalism. "The good savage" lives in harmony with the Eden-like ecosystems that are interpolated into the cartography of ecotourism' (Davidov, 2011, p. 470)

The treatment of indigenous peoples - including the implications of Native American iconography - provide an appropriative categorical gloss over the disenfranchisement of tropical peoples, and this 'moral right' of 'civilised' outsiders to colonise and displace 
becomes a normative feature of tropical environments and inhabitants in the first part of the period examined for this research paper. Veronica Davidov in The Exotic and the Wild argues that colonial discourses illuminate the extent of colonial preoccupation with the categories of culture and civilisation and the anxieties about the fluidity of inclusion and exclusion that belies such distinctions' (Davidov, 2011, p. 468). Postcolonial awareness of disturbing colonial heritage may influence later cover art choices by editors - polarised representations of aliens versus humans decline as we move towards the present (Figs. 20, 21, 22), reflecting an audience less preoccupied about inclusion and exclusion criteria for civilisation, and perhaps because science fiction today is at the forefront of literary movements that address a popular culture audience familiar with eroding traditional notions of gender, race and sexuality. There is an alternative explanation, which is that the notion of the Native American, for example, is no longer exotic, and no longer something 'that exists prior to its "discovery" (Mason, 1998, p. 1). Peter Mason adds: "It is the very act of discovery which produces the exotic as such and it produces it in varying degrees of wildness and domestication. In other words, the exotic is the product of the process of exoticization' (1998, p. 2). It may simply be that the myth of the Native American has been evaporated by historical and cultural change, and that is why it tends to be absent on later covers in the original 'noble savage' formulation.

\section{Limitations}

The volume of cover art examined is not exhaustive, but does represent a significant proportion of the total science fiction magazine corpus. It includes more than $40 \%$ of all professional and semi-professional science fiction magazine issues published in the twentieth century as indexed in the comprehensive Science Fiction, Fantasy, \& Weird Fiction Magazine Index (Miller, Contento, \& Stephensen-Payne, 2017), and complete or near-complete runs of all major titles. Digitised books were predominantly Ace publications (842 covers), and the availability of book covers was significantly lower than for magazines - although exact figures for science fiction book publishing are not available. The mixed methods approach employs digital tools alongside phenomenological interpretations to make the selection; and thus although reduced, subjectivity bias will still be present in the research design, and this is acknowledged. The hope is that a reduction in bias leads to novel conclusions, which is indeed the case here. The fact that desert and jungle environments have very distinct features ameliorates the problem of researcher bias, but there was also the necessity to decide which spaceships might be 'cities' based on personal experience of the genre. To reduce selection errors, inclusion criteria tended towards all examples of spaceships to avoid ambiguous classification on the basis of personal phenomenological bracketing. Choices had to be made on how to classify a 'tropical scene,' based on Earthly conventions, and the 'local' tropical was observed from the dress of the 
indigenous inhabitants. The covers shown in Fig. 6 and Fig. 9 are included as possible examples of tropical savanna, rather than being in a temperate-equivalent zone.

There is a fundamental problem in determining the tropics in a fictional alien environment, however, in that the classification of the tropical zone on Earth is historically arbitrary, based on Aristotelian cartography - which is clearly not translatable to other worlds. The differentiation between tropical and non-tropical in cover selection has been framed from a human, Earthly, perspective, which cannot be entirely removed from the process - requiring an explanation of the logic of assumptions indicated above regarding non-Earthly equivalence.

\section{Conclusions}

Portrayals of living cities in tropical settings are not commonly found in science fiction cover art, but can be categorised by the persistence of tropes - primitivism of Indigenous cultures, exploitative, simplistic depictions of women, and the prevalence of conflict. There is a difference between the portrayal of the tropical jungle compared to the tropical desert - the former exhibiting primitive cultural values, whereas desertdwellers appear more sophisticated and technologically advanced. None of the jungle dwelling people have cities of their own, and actively attempt to destroy civilised cities and structures. The only cities which appear to be Indigenous are in deserts or desertlike spaces, and are generally portrayed as ruins, not living cities. This follows 'lost civilisation' tropes, and reinforces the colonial assumptions that indigenous people are inferior, especially regarding cultures that are analogized to the history of colonisation and exploitation of the lands and peoples of indigenous cultures on Earth. We can see changes in cover art that reflect how popular perceptions and impressions of tropical cultures and peoples have developed over time from very simple tropes into more nuanced reflections, which may parallel the increasing understanding and knowledge that were disseminated among and between human cultures over the twentieth century. Intriguingly, the city retains its status as a center of civilisation, even when derelict, and to some degree isolated from, rather than continuous with, the tropical environment.

A valuable outcome of this study was the sharp relief afforded to the human cultural concept of the tropical world when considering what 'tropical' would signify on an alien world that had never known Aristotle, and did not have European colonial cartography. In these circumstances, we would not be talking only of the 'Tropics of the Imagination' - the tropics would be entirely imaginary, and only meaningful to a human other steeped in cultural convention. Our assumptions of the characteristics of the tropical environment are readily focused by this science fictional lens. We realise that 'the tropics' is not a term that arises from the indigenous peoples of alien worlds, any more 
than it should be assumed to be of relevance to the indigenous inhabitants of the cartographical 'torrid zone' of Earth.

\section{References}

Ashley, M. (2006). The age of the storytellers: British popular fiction magazines, 1880-1950. S.I.: British Library.

Barbour, C. (2015). When Captain America Was an Indian: Heroic Masculinity, National Identity, and Appropriation. The Journal of Popular Culture, 48(2), 269-284. doi:10.1111/jpcu.12256

Barthel, K. U. (2007). ImageSorter (Version 2.02). Berlin: Zentrum fur Mensch-MaschineKommunikation.

Blish, J. (1971). Cities in Flight. NY: Avon.

Byrd, J. A. (2007). "Living My Native Life Deadly": Red Lake, Ward Churchill, and the Discourses of Competing Genocides. American Indian Quarterly, 31(2), 310-332. doi:10.1353/aiq.2007.0018

Cartier-Bresson, H. (2015). The Decisive Moment. Gottingen, Germany: Steidl.

Cheng, J. (2012). Astounding wonder: Imagining science and science fiction in interwar America. Pennsylvania: University of Pennsylvania Press.

Clement, T. (2013). Text analysis, data mining, and visualizations in literary scholarship. MLA Commons. doi:10.1632/Isda.2013.8

Conor, L. (2006). This striking ornament of nature: The 'native belle' in the Australian colonial scene. Feminist Theory, 7(2), 197-218. doi:10.1177/1464700106064420

Davidov, V. (2011). From Colonial Primitivism to Ecoprimitivism: Constructing the Indigenous "Savage" in South America. arcadia, 46(2), 467.

Deckard, C. E. (1970). Letter. Fantastic, 20(2), 129-130.

Delany, S. R. (1965). City of a Thousand Suns. NY: Ace.

Deloria, P. J. (1998). Playing Indian. Newhaven: Yale UP.

Flanders, J. (2013). The literary, the humanistic, the digital: Toward a research agenda for digital literary studies. MLA Commons, 10. doi:10.1632/lsda.2013.9

Gibson, W. (1984). Neuromancer. NY: Ace.

Horseman, R. (1986). Race and manifest destiny. Cambridge MA: Harvard UP.

Karinthy, F. (2011). Chain-links The Structure and Dynamics of Networks (pp. 21-26). Princeton: Princeton University Press.

Liberati, A., Altman, D. G., Tetzlaff J., Mulrow C., Gøtzsche P. C., loannidis J. P. A., et al. (2009). The PRISMA statement for reporting systematic reviews and meta-analyses of studies that evaluate health care interventions: explanation and elaboration. PLoS Med, 6(7). doi:10.1371/journal.pmed.1000100

Lundberg, A. (2018). Editorial: Living cities: Tropical imaginaries. eTropic, 17(1), 1-5. doi: https://dx.doi.org/10.25120/etropic.17.1.2018.3638

Mason, P. (1998). Infelicities: Representations of the exotic. Baltimore: John Hopkins UP.

Menadue, C. B. (2017). Trysts tropiques: the torrid jungles of science fiction. eTropic, 16(1), 125-140. doi:https://dx.doi.org/10.25120/etropic.16.1.2017.3570

Menadue, C. B. (2018a). Hubbard bubble, dianetics trouble: An evaluation of the representations of dianetics and scientology in science fiction magazines from 1949 to 1999. [In Press].

Menadue, C. B. (2018b). @rts of D@rlcne55: A Pilgrim's Progress Towards a Humane Digital Methodology. [In Review].

Menadue, C. B., \& Cheer, K. D. (2017). Human culture and science fiction: a review of the literature, 1980-2016. SAGE Open, 7(3), 2158244017723690. doi:10.1177/2158244017723690 
Menadue, C. B., Giselsson, K., \& Guez, D. (2018). An empirical revision of the definition of science fiction: it's all in the techne. [In Review].

Menadue, C. B., \& Jacups, S. (2018). Who reads science fiction and fantasy, and how do they feel about science? Preliminary findings from an online survey. SAGE Open, 8(2), 2158244018780946. doi:10.1177/2158244018780946

Miller, S. T., Contento, W. G., \& Stephensen-Payne, P. (2017, 30th October 2017). The science fiction, fantasy, \& weird fiction magazine index. Retrieved from http://www.philsp.com/homeville/sfi/0start.htm

Naval Technology. (2018). Nimitz class aircraft carrier. Retrieved from https://www.navaltechnology.com/projects/nimitz/

Neville, R. (1971). The WH Smith story. OZ(36), 52.

Pearson, K. (1905). The problem of the random walk. Nature, 72(1865), 294-294. doi:10.1038/072294b0

Rajaniemi, H. (2010). The Quantum Thief. London: Victor Gollancz Ltd.

Rosaldo, R. (1989). Culture and truth: the remaking of social analysis. Boston: Beacon Press. Silverberg, R. (1962). The Seed of Earth. NY: Ace.

Slotkin, R. (1973). Regeneration through violence: The mythology of the American frontier 1600-1860. Norman: U of Oklahoma P.

Stevens, A., Shamseer, L., Weinstein, E., Yazdi, F., Turner, L., Thielman, J., . . . Moher, D. (2014). Relation of completeness of reporting of health research to journals' endorsement of reporting guidelines: systematic review. BMJ : British Medical Journal, 348.

Trumpener, K. (2009). Critical response. I. paratext and genre system: a response to Franco Moretti. Critical Inquiry, 36(1), 159-171. doi:10.1086/606126

Vinge, V. (1992). A fire upon the deep. NY: Tor. 